Int. J. Dev. Biol. 53: 1305-1316 (2009)

doi: $10.1387 / \mathrm{ijdb} .072425 \mathrm{jc}$

\title{
Segmentation, metamerism and the Cambrian explosion
}

\author{
JUAN PABLO COUSO* \\ School of Life Sciences, University of Sussex, Brighton, U.K.
}

\begin{abstract}
Data on the molecular and genetic basis of animal development, and on genome sequences, have been challenging our established assumptions about animal evolution for the last decade. Recent such data in animals of particular phylogenetic importance beg us to take another look at whether similarities in developmental and genetic mechanisms in current animals are the product of a common inheritance (homology) or convergent evolution (analogy). The evolution of segmentation, in particular whether segmentation and metameric bodies have arisen just once or several times in evolution, is a prime concern. Segmentation and metamerism are striking developmental and body organisations that exist, in varying degrees, in many complex animals, but the traditional view holds that this is the result of convergent evolution. Here, I review recent palenotological and developmental information and conclude that a metameric body plan is not only a likely ancestral character of bilaterian animals, but also a possible trigger for the Cambrian explosion in body morphology and complexity. This conclusion is supported by the phylogenetic distribution and prevalence of metameric phyla in the Cambrian, and the similarity of the genomes and segmentation mechanisms across current bilaterian phyla.
\end{abstract}

KEY WORDS: metamerism, segmentation, evolution, development, bilaterian ancestor

\section{Introduction}

Segmentation is a striking body organisation that exists, in varying degrees, in several groups of complex animals. It consists of the physical division of the body into units, the segments, each comprising a precise set of repeated, or metameric, organs. Segmentation and metamerism are not only functional, but also developmental phenomena, since they are implemented during early ontogeny by elaborate cellular and molecular processes that often influence profoundly the rest of development. Thus segmentation and metamerism have often been discussed in the contexts of developmental biology and evolution. The classical view on segmentation, based largely on morphological observations of adult and developing animals, holds that it evolved independently in annelids, arthropods and our own chordate phylum (Borradaile et al., 1963, Willmer, 1990, Brusca and Brusca, 2003). However, here I review emerging data on the genome sequences and mechanisms of development of animals of particular phylogenetic importance that invite us to reconsider the evolution of segmentation. In particular, the issue of whether segmentation and metameric bodies have arisen just once or several times during evolution emerges as a central question to understand the origin and evolution of bilaterian animals; it impinges on the question of whether the last common bilaterian ancestor was a complex or a simple animal, and of whether common features in animal developmental genetics are homologous and inherited from this ancestor, or were independently evolved in a convergent manner. The use of genetic information to approach these questions has been followed before, with both homology (De Robertis, 2008) versus convergence (Erwin and Davidson, 2002) being proposed as answers. After reviewing current fossil, genomic and developmental information I conclude that a metameric body organisation is not only a likely ancestral character of all bilaterian animals, but also was a possible trigger for the dramatic increase in body morphology and complexity commonly referred as the Cambrian explosion.

\section{Metamerism and segmentation}

The first problem encountered when discussing segmentation is a semantic one. Segmentation has an iconic, semi-mystical status among developmental and evolutionary biologists, and is often confused with metamerism or the existence of a simple serial pattern. For this review, I will apply the following definitions: a) in a serial pattern, a single organ or structure is repeated along the animal body without further functional or developmental consequences; b) Metamerismindicates the existence of at least two sets of such coordinated, serially repeated organs along the

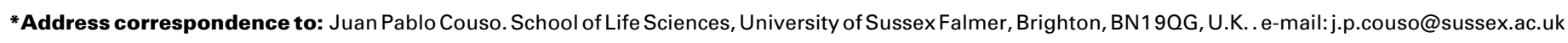

Final author-corrected PDF published online: 28 November 2008.

ISSN: Online 1696-3547, Print 0214-6282

(c) 2008 UBC Press

Printed in Spain 
main axis of the body, and assumes the existence of related patterning mechanisms; c) Segmentation is the most extreme example of metameric organisation and entails the metameric repetition of most organs of the body, such as in some cases the adult body itself seems formed by repeated physical units, the segments, composed by one instance of each type of metameric organ. Segmentation is often linked to specific developmental properties, such as cell lineage restrictions at segmental borders, and the ability of segments to behave as 'developmental fields', or units of regulation seemingly able to develop independently of the rest of the body (French, 1983). This definition of segmentation leads one to consider the individual metameric organs in a segment no longer as independent entities, because their devel- opment seems controlled through a hierarchically superior unit, the segment: the whole (segment) is taken instead of the parts (organs).

Two important points must be remembered. First, this extreme definition of the segment may only apply to a minority of existing species with metameric body organisation (probably only arthropods and annelids) (Budd, 2001). Second, even though segmentation is the extant body organisation in some animals, it is likely that the early stages in the evolution of segmentation entailed a simpler metameric organisation. This may seem an obvious statement, but often animals with simple metameric organisation are considered as simplified, 'degenerated' segmented ones, or else, evolutionary dead ends (Berg, 1985). In this review I take the view, supported by the many examples of metameric, yet non-segmented animals, that segmentation is the most extreme example of metamerism, and that it must have arisen by addition and developmental coordination of initially independently repeated organs. Organs must have been repeated in an ancestor before they accreted into segmental units: the segment did not arise as an empty compartment of the body later to be populated by organs (Lawrence and Johnston, 1989), even though this may be the developmental mechanism in extant segmented animals. In other words, the metameric organs preceded the segment, not the other way around. It follows that the important developmental and evolutionary innovation is metamerism, the developmental coordination of serially repeated organs or body parts along the main body axis, the jump from randomly or fractal repeated structures into orderly repeated units. Segmentation is just one of the possible evolutionary and developmental paths that metamerism can

B

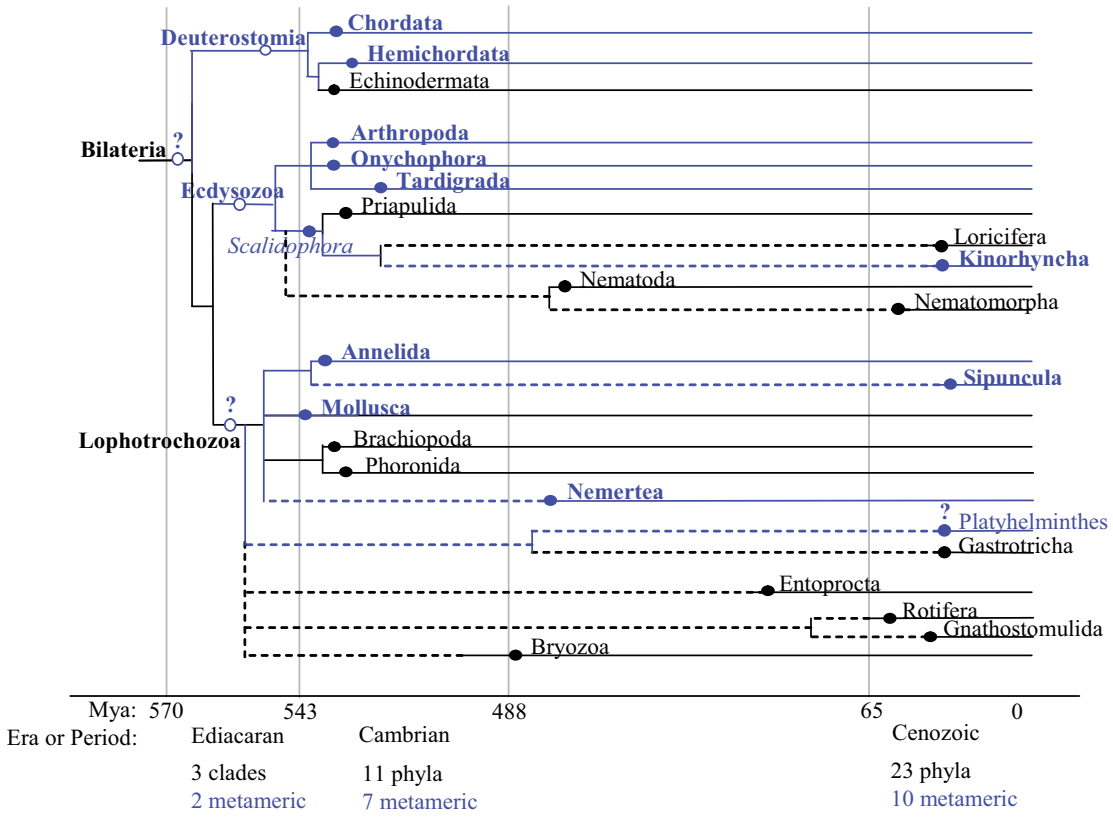

Fig. 1. Phylogenetic trees showing relationships between extant phyla. Solid circles, fossil ancestors of each clade; empty circles, hypothetical ones. (A) Classic phylogenetic tree ca. 1990, with segmented clades highlighted in green. Bilaterian animals are classified in increasing levels of morphological complexity. Extant phyla were thought to arise mainly around the Cambrian but following long previous evolutionary periods from simpler ancestors. (B) Modern phylogenetic tree arisen from studies of DNA sequence similarity. Metameric ancestors and clades are highlighted in blue. Phyla are placed at the time of their earliest appearance in the fossil record. Dotted lines show inferred previous evolutionary history. Branching points are timed according to modern calibrated DNA clocks, new fossil information, and cladistic inference (after Valentine et al., 1999, Peterson et al., 2005). Bilaterian animals appear after the glacial episode ca. 570, quickly split into three main lineages (Deuterostomes, Ecdysozoans and Lophotrochozoans) and evolve most of the extant body plans in the Cambrian (the 'Cambrian explosion'). Note the prevalence of metameric body plans in the Cambrian. 
take, as opposed to its stasis, out-of-register repetition or disappearance altogether (see text).

Making this distinction between metamerism and segmentation leads me to attribute to metamerism the postulated evolutionary advantages of segmentation, in particular, the availability of body units that can be repeated in varying numbers along the body (repetition), where units can follow independent specializations along the body of a given animal (serialization) or in different animals (specialization) (French, 1983, Akam, 1995, Carroll etal., 2001). In fact, a loosely metameric organisation is likely to be initially as plastic and evolutionary useful in this respect as a totally segmented body.

\section{Phylogeny of metamerism}

Recently, our understanding of the phylogenetic relationships of the major groups of bilaterian animals has changed dramatically (Aguinaldo et al., 1997, de Rosa et al., 1999, Halanych, 2004) but the implications of these changes have not yet permeated all aspects of Biology. The 'classic' phylogeny (Fig. 1A) illustrated a gradualist view, in which animals acquired increasing levels of body complexity, mostly judged by the existence and type of coelomic cavities and other morphological features. Plotting the existence of segmented bodies into such a phylogenetic tree seemed to indicate the independent emergence of segmentation twice, once in Chordates and another in the 'Articulata', an amalgam of arthropods and annelids in which the arthropod segmentation and body plan were seen as derived from annelid ones (Borradaile et al., 1963, Willmer, 1990, Budd, 2001, Brusca and Brusca, 2003). However, the' modern' phylogenetic tree (Fig. $1 B)$ arose from studies of DNA sequences, and splits animals roughly into three major lineages (Deuterostomia, Lophotrochozoa and Ecdysozoa) with seemingly few intermediate species, none with a complex body organisation (Adoutte, 1999, Erwin and Davidson, 2002). This new tree confronts us with two possibilities: either the common ancestor of bilaterian animals was very simple, and the three major lineages separated early on and independently evolved complex morphological characters; or their last common ancestor was complex and a host of descendant clades became simplified over time. It is not easy to solve this dilemma because complex characters shared by animals in each of the three main branches appear as discontinuities, and the judgement on what is homologous, or inherited from a common ancestor, and what is analogous, or independently evolved, is unclear and sometimes still seems to follow the assumptions of the 'classic', gradualist phylogenetic scheme (Brusca and Brusca, 2003). Thus, characters that follow this gradualist progression are often deemed ancestral, and characters that do not, convergent, regardless of their new phylogenetic distribution. Examples are eyes, coelom, metamerism, and nervous system organisation. In the old phylogeny, eyes appeared up to 12 times as seemingly unconnected, independent events, and thus the evolution of eyes was seen as convergent. However, the organisation of the nervous system was seen to gradually accrete from a diffuse neural network into centralised nervous systems once in the phylogeny, so a condensed CNS was deemed as ancestral. These two characters (eyes and condensed CNS) are still viewed as convergent and ancestral respectively when in fact, in view of the new phylogeny, they both arise apparently independently several times in both the deuterostome and protostome lineages (Lowe et al., 2003, Arendt, 2005, Lowe et al., 2006, Denes et al., 2007) and so both should be regarded equally as convergent. The coelomic cavities themselves, which are seen in the new phylogeny to have arise and disappeared independently several times, are still sometimes considered ancestral (Budd, 2001). We simply lack enough morphological information, fossil or otherwise, on the ontogeny and phylogeny of gain and loss of complex body structures and we must tackle this issue anew with the help of phylogenetic and developmental information. This approach must also be applied to study the ancestry of metamerism.

The deep evolutionary distance between arthropods, annelids and chordates in the new phylogeny seems to show segmentation now appearing independently in three out of a total of some 23 phyla (the number of bilaterian phyla is still debated). However a slightly different picture emerges if we focus on metamerism rather than segmentation (Fig. 1B). A number of non segmented phyla show reiterated structures along the main body axis which could either represent the ancestral condition (metameric rather than fully segmented), or serve as remnant markers of ancestral segmentation, in either extant (crown) or extinct (stem) members of the phyla. Cases in point are Molluscs, Nemerteans and Platyhelminthes.

With regard to Molluscs, the classes Monoplacophora and Polyplacophora (chitons) are among the most ancient members of the phylum and show clear signs of metameric organisation. The earliest moluscan fossils are Monoplacophoran, which could represent the stem group for this phylum and which show serially repeated muscle attachments (Runnegar and Pojeta, 1974). Neopilina, an extant monoplacophoran, indeed displays the corresponding metameric muscles, and in addition, metameric excretory and circulatory organs (although these ones are not in register with muscles) (Lemche, 1957, Borradaile et al., 1963, Jacobs et al., 2000). Polyplacophoran chitons show even more dramatic metamerism as their shell is divided into independently articulated 'segments' attached to the muscle metameres. Most interestingly, chitons show reiterated expression of the pansegmental maker engrailed (Patel et al., 1989) at the shell and muscle 'metamere' borders (Jacobs et al., 2000), similarly to Ecdysozoans (Fig. 2B)

Nemerteans, or ribbon worms, have serially repeated and coordinated structures in their bodies, such as gonads alternating with gut diverticula, circular muscles and transverse connective nerves (Brusca and Brusca, 2003). Interestingly, the gut diverticula are formed by constrictions of mesenchyma growing from the sides of the animal. These structures form full septa across the body similar to those of annelids in the new nemertean genera Annulonemertes(Berg, 1985) such as in effect, this nemertean is truly segmented. Even though in the new phylogenetic tree Nemerteans are no longer closely related to Platyhelminthes (flatworms), the serial structures mentioned above are also found in Platyhelminthes, albeit with a more variable and loose organisation. Without wanting to enter into a discussion of the phylogenetic position and affinities of flatworms (a perennial source of debate; see (Conway-Morris et al., 1985) their classic 'primitive' status has again been challenged (Ruiz-Trillo et al., 1999), and this should affect whether we consider their body plan as primitive, or simplified. Members of this phylum (Class Cestoda, tapeworms) have also achieved (or retained?) a segmented 
organisation, absent in non-parasitic species, traditionally considered less derived. This segmentation is however functionally very different to that of annelids or chordates, as it leads to excision of zooids (proglottids), and thus more akin to the strobilation of some medusae (Borradaile et al., 1963, Brusca and Brusca, 2003).

Thus, when studying the phylogenetic distribution of 'metameric' phyla (that is phyla containing either a majority or a significant proportion of species with metameric organisation), as opposed to segmented, the number of such phyla increase from 3 out of 24 , to possibly 10 out of 23 (Fig. 1B). This distribution still does not produce an immediate impression of relatedness or single origin for metamerism, but shows a more pervasive presence of serially repeated body plans. An even more suggestive picture is obtained when, instead of focusing on the morphology of crown extant members of the phyla, we concentrate on the morphology of the stem members, in particular, at the origin of bilaterian phyla in the Cambrian. Plotting the presence in the fossil record of the oldest stem members of existing phyla (Valentine et al., 1999), and whether their organization is metameric or not, reveals that 8 out of 11 phyla with Cambrian fossil record were metameric (Fig. $1 \mathrm{~B})$. This analysis is not meant to indicate that the other 12 modern phyla without such ancient fossil record did arise after the Cambrian, or from Cambrian phyla. DNA sequence and cladistic analyses prove otherwise (Fig. 1B) (Donoghue and Benton 2007), and so their absent fossil record must be a case of sampling bias or a case of misidentified ancestors. It means simply that we do not know the morphology or body plan of their stem ancestors, because only fossils can provide this information. Extant synapomorphies, or shared derived characters in these phyla, only indicate that a common ancestor had them, but do not indicate when these characters evolved. Further, absence of characters can not be distinguished from their loss. This is relevant because many non-metameric phyla display simple body plans that under the classic phylogeny were considered primitive, supported by subconscious 'march of progress' and 'ontogenetic recapitulation' thinking (Gould, 1977, Gould, 1989).

\section{Likelihood for the ancestral evolution of metamerism}

Concentrating on what we can learn from the phylogenetic tree at the Cambrian reveals a prevalence and phylogenetic likelihood of ancestral metamerism. Thus, the deuterostome clade appears as ancestrally metameric (with pharyngeal pouches, body septa and repeated gonads) with one instance of loss of metameric organisation (Echinoderms). The Ecdysozoa also appear as ancestrally metameric, with three instances of loss, one in the in the nematode/nematomorph clade and two in the scalidophora clade: the stem scalidophoran Markuelia was metameric (Dong et al., 2004) and the Kinorhyncha remain so, but metamerism has been lost in Priapulida and Loricifera (Borradaile et al., 1963, Conway-Morris et al., 1985, Brusca and Brusca, 2003). In the Lophotrochozoa the picture is more complex. The Annelida and Sipuncula lineage is metameric, and the molluscs also were ancestrally metameric as discussed above. The BrachiopodaPhoronida clade appears as non-metameric, whereas the Nemerteans show vestigial or incipient metameric organisation. Thus, an assemblage of these lineages (which one might call Polymera or Metameria, following (Valentine, 1973) might show a putative ancestral metamerism, lost twice in the later Mollusca and Brachiopoda-Phoronida clades. The sister superclade of Platyhelminthes and Gastrotricha would appear as a possible metameric loss. Finally, Entoprocta, Rotifera-Gnathostomulida and Bryozoa, all of uncertain phylogenetic affinities but possibly within the Lophotrochozoa, are all non-metameric.

With this picture, and under the hypothesis of an ancestral, single origin of metamerism in the last common bilaterian ancestor, metamerism would have evolved once, and been lost up to10 times (Echinoderms, Priapulida, Loricifera, Nematoda, Mollusca, Brachiopoda-Phoronida, Gastrotricha, Entoprocta, RotiferaGnathostomulida, and Bryozoans). However, applying the traditional hypothesis of convergently evolved segmentation and metamerism to the new phylogeny forces us to accept that metamerism should have evolved independently at least 6 times (Deuterostomes, pan-Arthropods, Annelids, Molluscs, Scalidophorans and Nemerteans) and secondarily lost 5 times (Echinoderms, Priapulids, Loriciferans, Nematods, and Molluscs). Neither picture is totally satisfactory. The hypothesis of convergent evolution of metamerism would have to explain convergent evolution and convergent loss, whereas the hypothesis of ancestral homologous metamerism would have to account for apparently widespread losses.

It is interesting that several clades that currently appear as non-metameric in Fig. 1B have undergone dramatic specializations in other areas of their body plans, or in their functionality and life strategy, away from the typical bilaterian model. Likely selective pressures and response strategies that might have conceivably led to the evolution of bilateral organisms are purposeful anterior-posterior movement over the substrate (explaining the evolution of a dorsal-ventral axis of symmetry and the appearance of fossil tracks ca. 555 Mya), leading to a sensory focus (explaining cephalisation, or concentration of sensory organs at the head or anterior end of the animal) and to neuralisation (growth and condensation of the nervous system near the sensory focus, forming a CNS and a brain), all of which allowed, benefited or followed the appearance of predation (Collins and Valentine,
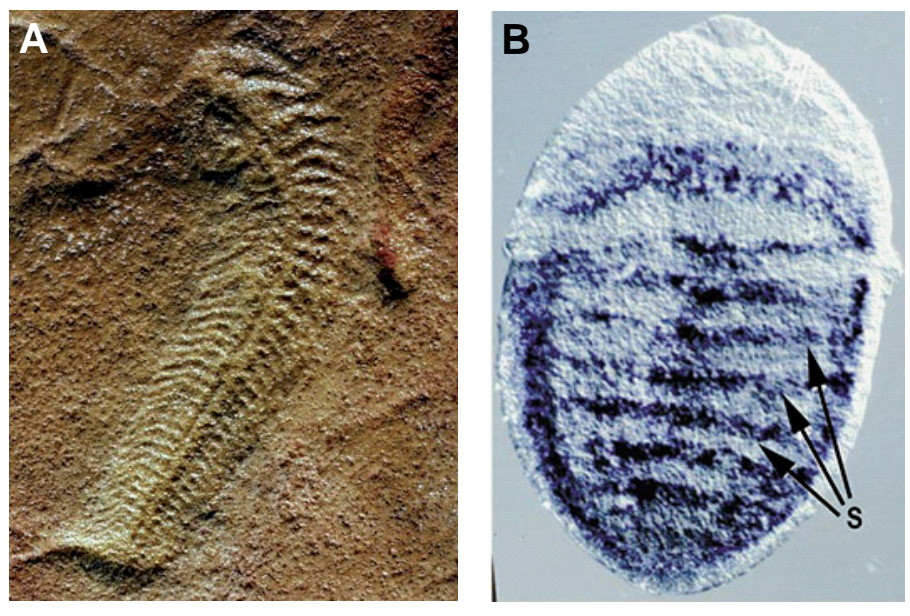

Fig. 2. Examples of metameric body organization. (A) The Ediacaran fossil Spriggina, a putative annelid or arthropod ancestor (from http:// www. toyen.uio.no). (B) Expression of the engrailed gene in a developing chiton at shell 'segment' boundaries (S) (modified from Jacobs et al., 2000). 
2001, Jacobs et al., 2005, Peterson et al., 2005, Butterfield, 2007). In contrast, the less motile Echinoderms have switched to radial body symmetry; Priapulida, Mollusca, and BrachiopodaPhoronida, have sessile, sedentary or slow-moving lifestyles; Entoprocta and Bryozoans are sessile and colonial. Thus, there seems to be a correlation between metamerism and mobility and it is logical to argue that a) ancestral motile bilaterians were metameric, and b) metamerism has been lost often and independently whenever a phylum became more sedentary. A second evolutionary specialization conductive to loss of metamerism could have been parasitism, as seen in Nematods and Platyhelminthes. In any case and as mentioned before, some of these non-metameric clades do not have Cambrian fossil records, so we do not know when their non-metameric body plans actually evolved.

In summary, when considering the big phylogenetic picture, the hypothesis of ancestral metamerism appears at least as parsimonious as the idea of its repeated and convergent evolution. In my view we can resolve this stand-off by studying the genetic-molecular implications of gain versus loss of metamerism, and I will address this topic in the sections on "Notch signaling is a conserved metameric mechanism" and "Why Notch? $A$ gradual model for the evolution of Notch-mediated metamerism" of this review. However, first I will discuss the further implications of a putative metameric ancestor for bilaterian animals, particularly with relevance to the Cambrian explosion.

\section{Metamerism as a trigger for the Cambrian explosion}

The fossil record registers the often-mentioned 'Cambrian explosion' which refers to the sudden appearance of complex body forms in the Cambrian without clear fossil antecedents (Gould, 1989, Butterfield, 1994, Collins and Valentine, 2001, Jacobs et al., 2005, Peterson et al., 2005, Butterfield, 2007) (Fig. 1B). A sudden appearance of body forms has been traditionally regarded with suspicion and attributed to gaps in the fossil record. Pre-Cambrian Ediacaran fossils contain mostly strange body plans apparently unrelated to extant animals, but also a few that could be recognised as metazoan ancestors. The Ediacaran faunas were, and still are, considered to be mostly composed of dead-end bizarre offshoots of the metazoan lineage, or nonmetazoan (colonial) organisms, despite the occasional presence of putative bilaterian forms (Fig. 2A) (Valentine, 2002, Seilacher et al., 2005, Butterfield, 2007, Droser and Gehling, 2008).

An endless debate has raged about the reality of this Cambrian explosion. 'Molecular clock' studies of DNA sequences have been used to date the split between the main metazoan branches. A split much earlier than the Cambrian boundary would deny the existence of an acceleration, or explosion, in the rate of evolution of body plans, whereas a split close to the Cambrian would confirm the fossil record (Peterson et al., 2005). The results of using new, calibrated 'molecular clock' methods (Bromham, 2003, Peterson and Butterfield, 2005, Donoghue and Benton, 2007) join the growing consensus about the reality of this explosion, but the explanations for it remain conjectural and problematic. A sensible hypothesis must incorporate factors both endogenous (suddenly flexible or more sophisticated developmental gene networks) and external (rising $\mathrm{O}_{2}$ levels in the environment, new ecological niches available) (Peterson et al., 2005, Bambach et al., 2007,
Butterfield, 2007). Exciting new fossil discoveries in the last decade now present a more continuous paleontological record across the Cambrian boundary, showing initially rare and simple, but increasingly complex and abundant, metazoan presence from around 580 Mya, coincident with an unequivocal change in faunas and ecology (Peterson and Butterfield, 2005, Seilacher et al., 2005, Bambach et al., 2007, Butterfield, 2007). In particular, the period from 630 Mya to 530 Mya shows a change from a Neoproterozoic ecology dominated by unicellular, mostly prokaryote, organisms thriving in an uniform and $\mathrm{O}_{2}$-poor environment, to an ecology dominated by metazoan eukaryotes in an $\mathrm{O}_{2}$-rich atmosphere, with region-specific faunas and environments. This period is likely to have followed a severe and global glacial episode (Snowball Earth) as late as 600-570 Mya and shows first, the appearance of Ediacaran organisms with fractal body organisation, and then, starting at about $555 \mathrm{My}$, possible bilaterian ancestors and trace fossils. These traces in the sediment become deeper and larger, and more interactive (Seilacher et al., 2005), and then hard skeletons and true bilaterian fossils of many crown phyla appear in quick succession in the period 543 to 520 Mya (early Cambrian) (Fig. 1B), accompanied by their dramatic increase in diversity and size.

A further fact that supports a Cambrian explosion and the rapid evolution of a complex, metameric common ancestor is the fast split between Deuterostomia, Lophotrochozoa and Ecdysozoa. It appears that the synapomorphies of each of these three superclades evolved quickly, including features such as inversion of the dorsal-ventral axis, evolution of the deuterostome mouth, superclade-specific larval forms and skeletons, ecdysis, etc. Therefore, it would seem perfectly possible that characters shared by these three taxa (three germ layers, bilateral symmetry, though gut, cephalisation, AP axis containing several regions controlled by a Hox cluster, (Baguña and Riutort, 2004); plus as postulated here, metamerism) evolved similarly fast. The early Cambrian Burgess Shale and Chiengjiang fossil faunas show that the full panoply of pan-Arthropoda adaptations had evolved and was been exploited to the full, creating a morphological diversity similar to that amongst current arthropods but in the shorter period of about 50 Mya (Gould, 1989, Briggs et al., 1992).

Increase in body size and complexity to the macroscopic brings well-known physiological problems that require the existence of circulatory, sensory, excretory and respiratory systems covering the body. There are three ways to deploy these: by 1) even spacing, 2) fractal branching patterns (Mitchison, 1980; Metzger et al., 2008), and 3) orderly repetition. Even spacing is achieved in development by random lateral inhibition (Wigglesworth, 1940; Heitzler and Simpson, 1991), which is fine for covering an epithelium with sensory organs or glands, but is not appropriate for systems requiring directional connectivity, such as veins or nerves. Such directional connectivity is achieved by fractal branching patterns, but this mechanism is not conductive to creating singularities, and seems to have been exploited extensively by Ediacaran organisms which could achieve a very large size (up to 1-2 meters) but without signs of regional specialization. Lastly, orderly repetition is achieved in animals through metamerism, which appears to be the easiest way to achieve expansion of the body along a defined axis. In addition, metamerism is the best way to achieve regional differences along such axis, once coupled to a device for serial specialization. This 
device existed at the dawn of the Cambrian. It was the Hox cluster.

\section{Ancestral Hox clusters and complex genomes}

The ancestral status of Hox-mediated AP body patterning is widely accepted, and has surprisingly been found in basal bilaterians (Cook et al., 2004) and even in diblastic animals (Technau et al., 2005, Chourrout et al., 2006, Ryan et al., 2007). The comparison of Hox clusters across bilaterians suggests an ancestral cluster with 3-4 genes (Ferrier and Minguillon, 2003, Garcia-Fernandez, 2005, Putnam et al., 2007). The implication is that regionalisation of the body was established by the time of the split between Deuterostomes, Lophotrochozoans and Ecdysozoans. Further, it is likely that the ancestral protoHox cluster was composed of at least three genes because acoels have 3 Hox genes clustered (Ferrier and Minguillon, 2003, Cook et al., 2004, Garcia-Fernandez, 2005). Since basal Hox genes already show regional patterns of expression in cnidarians (Technau et al., 2005, Chourrout et al., 2006, Ryan et al., 2007), it follows that the bilaterian ancestor body was probably already differentiated into three or four regions along the AP axis.

Such regionalisation implies either the previous existence of patterning boundaries, or else regionalisation itself creates such pattern discontinuities between the regions defined. Either situation could act as a prepattern for the establishment of metameric boundaries. Interestingly, the full advantages of a metameric organisation are achieved when serial differences (different features in different metameres) are introduced by Hox genes, and reciprocally, the full advantages of Hox-based regional specification are achieved when the regions specified are coupled, or become, metameres (French, 1983, Akam, 1995). This would explain the persistence of segmentation and Hox regionalization in chordates and arthropods, as independently controlled, yet developmentally coordinated, processes (Akam, 1987, Akam, 1995, Zakany et al., 2001). The key point is that, in the absence of metamerism, Hox genes cannot instruct a serial body plan organisation, and must remain as simple cell-type switches, the roles found in current cnidarians and in other bilaterian genes (such as Lox or cut) possessing the Hox domain but not being members of the Hox or ParaHox clusters (Arendt, 2005). Since the Hox cluster appeared earlier than the Cambrian it may have been a prerequisite for the Cambrian explosion, but not a trigger. A trigger might have been either the evolution of metamerism, or the coupling between metamerism and Hox regionalisation. How likely is that metamerism was present in the ancestral bilaterians?

Further information about the genomic toolkit available to the bilaterian ancestor has come to light. The genome of diblastic animals is been sequenced, and in some cases information on profiles of gene expression is available. In both case the surprising finding is that the diblastic ancestor was very complex genetically; as complex as current triblastic animals (Lee et al., 2006, Putnam et al., 2007). Around 1,600 metazoan-specific new gene families had accumulated during the Neoproterozoic (1000 to 600 Mya), whereas only a maximum of 600 bilaterian-specific genes appeared during
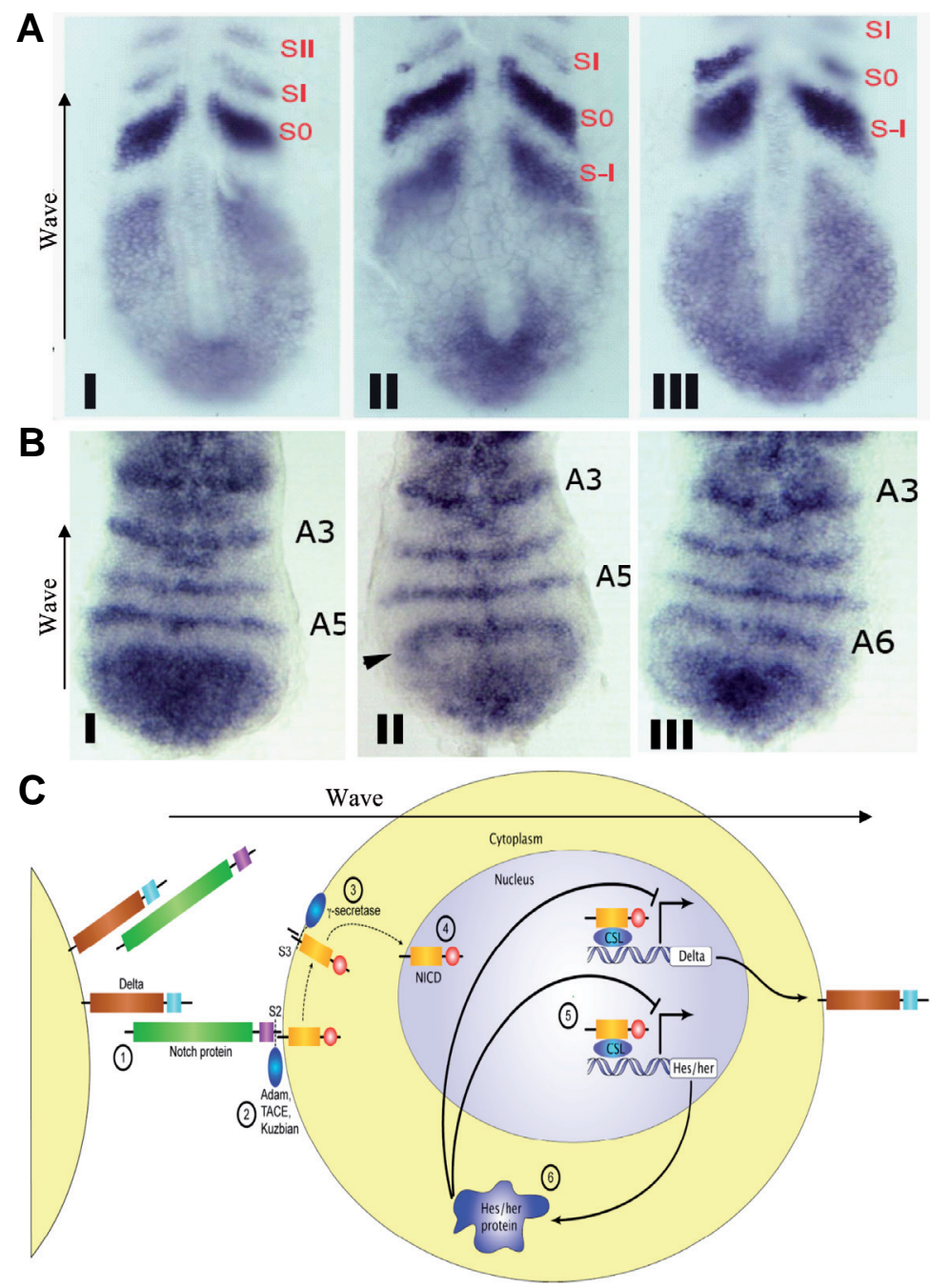

Fig. 3. Notch signalling generates patterning waves and metameric borders. (A) Cyclic HES-1 gene expression in a vertebrate chick embryo at three consecutive stages (I, II and III) covering a full cycle and the generation of a new somite. A wave of HES-1 expression travels from the posterior presomitic mesoderm (bottom) towards the segmented part (top) (from Jiang et al., 2000) and gives raise to the somites (S-1 to SII). (B) Cyclic hairy gene expression in a roach insect embryo covering the generation of a new segment (from (Pueyo et al., 2008). A wave similar to that of vertebrates (compare with A) travels from the unsegmented, posterior part of the embryo (bottom) and generates segments (A3 to A6) further up. (C) The Notch pathway (Bray, 2006) acts as a clock and wave generator through its negative feedback activity. A cell-to-cell signal is conveyed by the Notch ligand Delta (1), and transduced by a signalling mechanism involving cleavage $\mathbf{( 2 , 3 )}$ and translocation of Notch to the nucleus (4), where it forms a complex with the $\mathrm{Su}(\mathrm{H}) / C S L$ protein and activates expression of the Delta and HES/hairy genes (5). From here a feedback-loop acts as HES proteins repress both Delta and their own transcription (6). The result of these genetic interactions is a 'runaway' wave (running in this diagram from left to right) whereby a) Delta signalling cells activate HES and hence Delta expression in neighbouring cells, b) HES and Delta switch off in the original sending cells; $c$ ) the receiving cells now become the new sending ones, such as the 'wave' of HES activity has moved one row of cells. In the case of vertebrates, the regulatory activity of the Fringe protein, also regulated by Notch and HES, ensures that the wave does not travel backwards. 
the Ediacaran/Cambrian transition period (Putnam et al., 2007). The genetic resources making possible bilateral bodies (JimenezGuri et al., 2007) and complex triblastic body patterns were available at the dawn of the Cambrian.

Ignoring preconception, and a good deal of detailed morphological differences between extant bilaterian animals (since as we have seen these accumulated rapidly since the split of the three main lineages), it seems plausible that an ancestral bilaterian could have been complex. It is important to reiterate that this hypothetical ancestor was not the earliestidentifiable bilaterian (a position possibly occupied by the stem group of current Acoela flatworms (Ruiz-Trillo et al., 1999)), but the lastcommon ancestor of Deuterostomes, Ecdysozoans, and Lophotrochozoans (what has been called either the Urbilateria (De Robertis, 1997), the Protostome-Deuterostome ancestor (Erwin and Davidson, 2002), or the last common Eubilateria (Baguña and Riutort, 2004)). It did not spring directly from an ancestral diblastic cnidarian, but arose from that first bilaterian following at least 30 Mya of rapid evolution under the special conditions at the Ediacaran/Cambrian boundary.

What genetic mechanism could have allowed the evolution of a complex, metameric, bilaterian ancestor? Returning to the section of this review entitled "Likelihood for the ancestral evolution of metamerism", do the same genetic mechanisms underlie metamerism in extant phyla-suggesting conservation? If so, how easy would be to convergently evolve such shared genetic characters, as opposed to losing them?

\section{Notch signalling is a conserved metameric mechanism}

The causal genetics of segmentation in chordates and arthropods have been partially unravelled. The segmentation of chordates is driven by a clock and wavefront mechanism mediated by HES/hairygene expression and coordinated by the Notch cell signalling pathway (Fig. 3) (Jiang et al., 2000, Pourquie, 2003). Briefly a cell-to-cell signal is conveyed by a Notch ligand such as the Delta protein, and transduced by a signalling mechanism feeding on the $\mathrm{Su}(\mathrm{H}) / \mathrm{CSL}$ protein and thence on target genes of the hairy/HES family of transcription factors (Bray, 2006). The expression of these genes cycles in a coordinated and rhythmic manner in the unsegmented posterior end of the embryo, and stripes of HES expression periodically leave this region and travel as a wave through the more anterior unsegmented mesoderm, until they reach the last formed segment, or somite (Fig. 3A). It then stops and leads to the establishment of a new somite border. This behaviour relies on the self-regulatory nature of the Notch pathway and its HES targets (Fig. 3C).

Segmentation in arthropods has been regarded as mediated by a different mechanism. Studies in Drosophila have shown how a segmentation cascade subdivides the embryo using basic polarity information present in the unfertilised egg. All segments form simultaneously, determined by different and specific combinations of transcription factors, without any role for Notch-mediated cell communication (Akam, 1987, Ingham, 1988, Carroll, 1990, Jaynes and Fujioka, 2004). This model, with variations in the particular roles played by particular genes, has been upheld in other insects (Tautz, 2004, Choe et al., 2006). However, in the spider Cupiennius salei, Notch signalling controls segmentation via hairy expression (Stollewerk et al., 2003, Schoppmeier and
Damen, 2005). In the absence of another data point, it was not possible to decide what was the ancestral condition for arthropods. However, we have recently shown that Notch signalling via hairy controls segmentation in the basal insect Periplaneta americana, thus showing this to be the ancestral condition for arthropods (Pueyo et al., 2008) (Fig. 3B), a conclusion also supported by cyclic patterns of expression found in Myriapods (Chipman and Akam, 2008). Interestingly, similar dynamic expression of Notch pathway members has been reported in the growth zone of annelids, although no functional information is yet available (Rivera et al., 2005, Thamm and Seaver, 2008).

This findings immediately beg the question of the possible homology between chordate and arthropod segmentation. Several caveats to a possible homology must be considered. First, the primary segmented germ layer in chordates is mesoderm, but in arthropods is ectoderm. This caveat is easily overcome by thinking that ancestral segmentation might have occurred in both germ layers, and that the dominance of one germ-layer evolved independently in each lineage as a logical mechanism to ensure full register between both sets of segments, ectodermal and mesodermal. A second, and more serious caveat points out the very different architecture and development of chordate and arthropod embryos. It would seem implausible that segmentation would have been evolved in an ancestor and conserved in the face of many changes in subsequent evolution, or that segmentation would have evolved prior to say, dorsal-ventral (DV) organisation or CNS condensation. Recent genetic results can help to overcome this caveat which is again based on old phylogenetic assumptions based on extant morphologies. The bilaterian DV organisation may be homologous and ancestral after all (Lowe et al., 2006), with arthropods and chordates having simply inverted their orientation towards the substrate; CNS condensation seems to have indeed evolved independently and after the split between chordates and protostomes (Lowe et al., 2003), even though neuronal types may be conserved (Arendt, 2005). Thus these features were present in the hypothetical ancestor and are conserved despite drastic and highly divergent changes to embryonic architecture. Furthermore, retaking the main premise of this review, if we focus on metamerism instead of segmentation, this caveat becomes a non-issue. If the ancestral condition was a basic metameric organisation amenable to Hox control and subsequent elaboration (or loss), then segmentation could have arisen afterwards independently in arthropods, annelids and vertebrates as a logical culmination of metameric and Hox-based evolution, and in different manners reflected in divergent embryonic body plans. The ancestral bilaterian synapomorphism could be a simple metameric organisation similar to that displayed by current metameric molluscs or by Kinorhynchs, and could correlate with an ancestral mode of development based on terminal addition (Hughes, 2003, Jacobs et al., 2005).

Even accepting that Notch signalling can provide the genetic basis for an homology of bilaterian metamerism, the alternative hypotheses of independent convergent evolution has to be considered. This hypothesis argues that Notch signalling is a notoriously pleiotropic signalling pathway, that one of its main functions is to create patterning borders, and that therefore it might have been independently recruited for creating segments in several lineages. In addition, the dynamic of genetic network generation may create a bias towards the convergent evolution of certain 
networks (Erwin and Davidson, 2002), in a short of 'tunnelling' selection. However, the argument that Notch is the main boundary-making pathway is circular since one of the main types of boundaries it creates is segments. Once these are excluded, only two other types of Notch-mediated boundaries are left, one

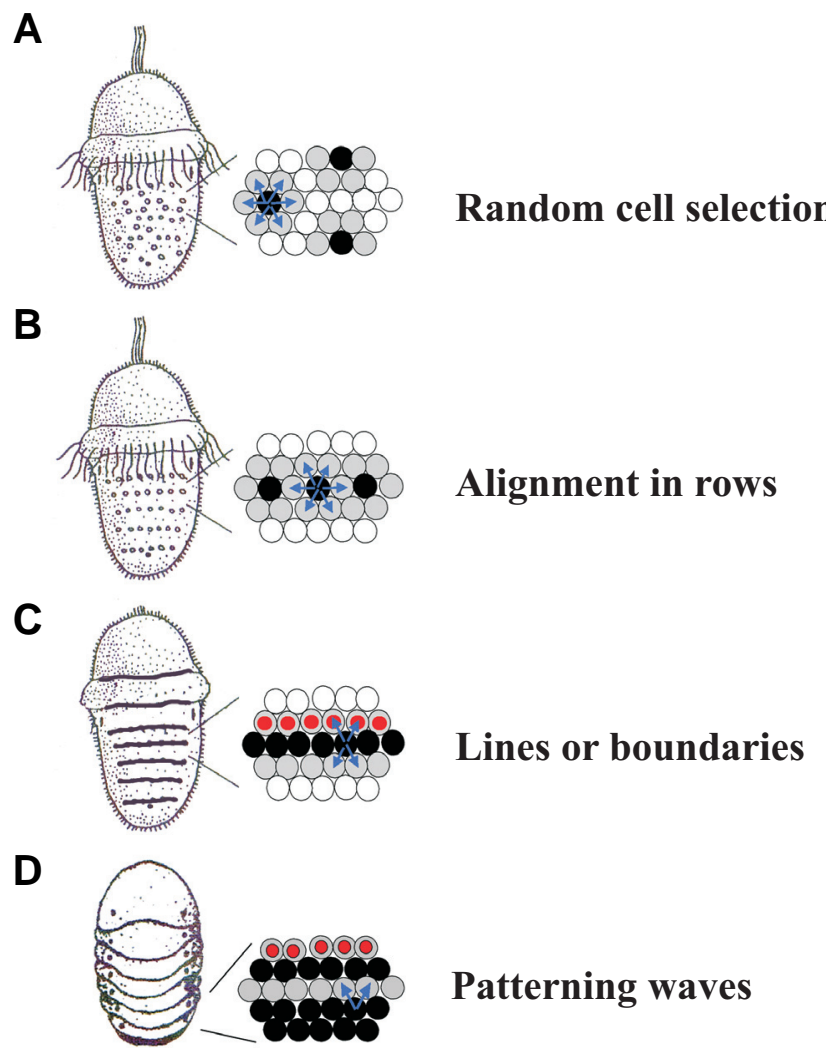

Fig. 4. Putative evolution of Notch signalling. Black circles, Notchligand expressing cells; grey and red circles, responding cells; short blue arrows, cell communication between a single Notch-ligand expressing cells and its neighbours. (A) Segregation of sensory elements (black) or other isolated pattern elements from clusters of competent cells (grey) at random by a mechanism of lateral inhibition. Single cells achieve a neural fate (black) and use Notch signalling to repress neural fate in their neighbours (grey). Examples are sensory bristles in Drosophila and other flies (Heitzler and Simpson, 1991, Campuzano and Modolell, 1992, Pistillo et al., 2002) and inner ear sensory cells in vertebrates (Adam et al., 1998). (B) Alignment of such competent clusters (grey) and selected elements (black) in rows, as in the bristles at the anterior wing margin of Drosophila (Couso et al., 1994) or, hypothetically, goblet cells in chitons (Jacobs et al., 2000). (C) Patterning of lines or boundaries, as in the fly veins (de Celis et al., 1997). The veins carry some neural and sensory cells but the cells in between these are not excluded, thus whole lines of cells are selected (black). In turn, these cells can convey further signals to some neighbours (red), as in the dorsal-ventral wing boundary of Drosophila (Couso et al., 1995, Kimet al., 1995) and vertebrate limbs (RodríguezEsteban et al., 1997). (D) Patterning waves, as in the segmentation clock. Once cells in patterning boundaries gain the ability to signal to adjacent cells, they recruit more cells and fates (red) to the boundary. If one of the signals passed on is Notch pathway cyclic activation (as in Fig. 3), then a runaway patterning wave is created (black and grey). This can generate a series of metameric boundaries along the main body axis (Jiang et al., 2000, Pueyo et al., 2008). Diagrams modified from (Jacobs et al., 2000) showing stages in chiton development, from trochophora larvae to adult. common to arthropods and vertebrates (the limb DV boundary) (Irvine and Wieschaus, 1994, Couso et al., 1995, RodríguezEsteban et al., 1997) and another specific to arthropods (leg joints) (de Celis et al., 1998, Bishop et al., 1999, Rauskolb and Irvine, 1999). Further boundaries in both lineages are created by other genetic mechanisms, such as hedgehog signalling at the limb AP boundary (Riddle et al., 1993, Ingham and Fietz, 1995); $w g / W n t$ signalling at the arthropod parasegment (Martinez-Arias, 1993); FGF signalling in vertebrate branchial arches (Trainor et al., 2002); and otx/Otd-emx/ems patterning in cephalic segments in arthropods and vertebrates (Reichert and Simeone 2001). There are also examples of clock and wavefront mechanisms, such as the morphogenetic furrow of compound insects eyes and the vertebrate limb, driven by other types of signalling (EGFR and FGF respectively) (Tomlinson, 1988, Simon et al. 1991, Cohn and Tickle, 1996, Wolpert, 2002). A recount of aforementioned developmental borders in insects shows that although Notch is often involved in borders, is not overwhelmingly so (3 out of 7 cases mentioned above). Using this number as a rough probability for Notch to be co-opted to generate any newly-evolved border, shows that the probability of Notch having been independently recruited for chordate and arthropod segmentation is about one in five $(3 / 7 \times 3 / 7=9 / 49)$. This probability is even lower if we consider the probability for other genes, non-core members of the Notch pathway, to have been recruited as well, such as HES/hairyitself. In different developmental contexts, Notch uses different transcription factors as targets, and so each of the Notch-mediated border-making processes mentioned above involves a different target (HES/hairy, vestigial and $E$ (spl) respectively). The same holds for vertebrates as HES is the target in somites, but not in limbs.

This brings us back to the last, and allegedly main, caveat against a putative common ancestry of metamerism: is this the most parsimonious explanation for the phylogenetic pattern of metameric and non-metameric phyla? In answering this question again from a genetic point of view, I argue that the probability of loss of Notch segmentation is necessarily higher than the probability of gaining it; is a simple question of entropy. All that is needed to lose Notch segmentation is to lose the function or expression of one member of the pathway, or one of its targets, in the segmented tissue. This principle of evolutionary developmental loss and recovery due to single gene function loss holds for amphibian metamorphosis (Gould, 1977), snake legs (Cohn and Tickle, 1999) and insect pigmentation (Jeong et al., 2006, Jeong et al., 2008) and it can be achieved by a single nucleotide change or by whole gene loss, a mechanism that seems much more prevalent in evolution than previously envisaged (Putnam et al., 2007) (Ferrier and Minguillon, 2003). Further, this probability increases with every gene and protein involved in a particular developmental pathway, and it would seem that the ancestral bilaterian Notch pathway was already composed of at least 7 proteins and hairy itself (Käsbauer et al., 2007, Putnam et al., 2007). In contrast, to co-opt the Notch pathway for segmentation at least two advantageous mutations in enhancer regulatory regions need to co-evolve, one in a Notch ligand (to make it expressed in the unsegmented tissue and/or responsive to HES/ hairy protein) and another in HES/hairy itself (to make it expressed in the unsegmented tissue and responsive to $\mathrm{Su}(\mathrm{H}) /$ $\mathrm{CSL})$. Since in principle the probability of deleterious mutation is 
much higher than that of adaptive mutation (reviewed by (EyreWalker and Keightley, 2007)), it is far more likely to obtain a deleterious mutation anywhere in a target of 7 genes than to obtain two simultaneous adaptive mutations in a target of three genes (two Notch ligands and HES). Thus, it is more likely for a given clade to lose function of Notch in the segments, than to gain it, and therefore, is appears more likely that 10 clades lost it, than 6 gained it and 5 lost it. Note that, although this reasoning uses the Notch pathway as an example, it could be used to test other genetic pathways to determine if the structures they generate in different clades are homologous.

\section{Why Notch? A gradual model for the evolution of Notch-mediated metamerism}

How could Notch signalling have acquired the ability to promote metameric organisation in bilaterians? engrailed gene expression in chitons is found associated with specialised secretory cells (Jacobs et al., 2000), and this, together with knowledge of the varied functions of Notch in insect and vertebrate development, provides the basis for a possible evolution of Notch roles (Fig. 4). The most ancestral process controlled by Notch is likely to be the lateral inhibition during the selection of neural cells (Heitzler and Simpson, 1991, Campuzano and Modolell, 1992, Chitnis et al., 1995, Lewis, 1998), because a) this function of Notch is essentially similar in vertebrates and insects, and b) because neural cell development in cnidarians predates the appearance of metamerism. Lateral inhibition can occur in isolated small clusters of cells, thus leading to the selection of a single proneural cell (Fig. 4A) (Cubas et al., 1991, Skeath and Carroll, 1991, Adam etal., 1998, Wulbeck and Simpson, 2000), or in larger groups leading to selection of more cells (Hartenstein and Posakony, 1989, Couso et al., 1994). Frequently these clusters are disposed in elongated stripes, following in some way a prepatterning clue (the situation in insect veins (de Celis et al., 1997)) (Fig. 4B). From here is a small jump to a boundary-making activity where Notch additionally selects a population of boundary cells (the situation in insects DV wing boundaries (Couso et al., 1994,1995, Kim et al., 1995), leg joints (de Celis et al., 1998, Bishop et al., 1999, Rauskolb and Irvine, 1999) and vertebrate rhombomeres (Lewis, 1998) (Fig. 4C) or even forfeits altogether its ancestral neural role to be dedicated to this new, boundarymaking activity (as in vertebrate somites (Jiang et al., 2000) and arthropod segments (Stollewerk et al., 2003, Pueyo et al., 2008)). Once metameric patterning borders have been established, other pattern elements and structures can become associated with it, such as serial muscles and their attachments (Fig. 4D). The appearance of a morphological groove at these boundaries would also be a secondary consequence of Notch involvement, because proneural cells (Hartenstein and Posakony, 1989) and other Notch-selected cells (Hao et al., 2003) often delaminate or invaginate from the external ectoderm.

During the evolution of these Notch functions, the effects of Notch signalling vary, from a repressive signal as involved in lateral inhibition, to the positive patterning signal seen in boundary-making activities. This change seems based on a simple switch in the main target gene whose transcription is activated by Notch. During Drosophila lateral inhibition the target is $E(s p l)$ (Kramatschek and Campos-Ortega, 1994) and this activity and genetic target is widely conserved, including animals without metameric organisation. The $E(s p l)$ genes are mostly transcriptional repressors of the HES family, whose main function during neurogenesis is to repress proneural gene expression (Kramatschek and Campos-Ortega, 1994). During segmentation, the target of Notch is instead hairy/HES-1, a gene related to $E(s p l)$. The hairy/HES protein also represses other repressor genes (Jaynes and Fujioka, 2004), hence this 'repression of a repressor' results in a positive patterning signal. Thus, a gene duplication event in the $E(s p l)$ family, giving rise to the protoHES1/hairygene, followed by divergence in the encoded protein so that it recognises further DNA target sequences, is the main change needed for the evolution of Notch-mediated positive patterning. An accurate phylogeny of $H E S / h a i r y / E(s p l)$ gene sequences should show whether this event happened once in animal ancestry, and when. Following the reasoning before, the subsequent deployment of hairy gene expression in developing metameres, and its coordination with an internal cellular oscillator as seen in chordates and arthropods, are more complex events, and thus even more unlikely to have evolved independently several times.

\section{Conclusions}

1) Metamerism was both present and prevalent during the Cambrian explosion.

2) Metamerism, in connection with Hox-mediated patterning, could have been a trigger for the Cambrian explosion in body plan diversity.

3) Metamerism is difficult to evolve, but easy to lose, and easy to modify into segmentation.

4) Notch signalling could underpin an ancestral metameric organisation in bilaterians.

This last conclusion can provide a molecular test of these hypotheses by checking a) whether Notch signalling underlies metamerism in segmented Lophotrochozoans and in non-segmented metameric clades; b) whether Notch signalling is still active in the germ band of non-overtly metameric species, and c) whether evolution of the hairygene correlates with the evolution of metameric body plans.

\section{Acknowledgements}

I thank Claudio Alonso, David Ferrier, Rob Lanfear and Inaki Pueyo for comments, discussions, ideas and unpublished data, an anonymous referee for extensive constructive comments, and Jaume Baguña for an extended correspondence on ancestral segmentation (or the lack of). I wish also to apologise to those authors whose relevant work is not quoted as there are already over 100 references in the manuscript.

\section{References}

ADAM, J., MYAT, A., LE ROUX, I., EDDISON, M., HENRIQUE, D., ISH-HOROWICZ, D. and LEWIS, J. (1998). Cell fate choices and the expression of Notch, Delta and Serrate homologues in the chick inner ear: parallels with Drosophila senseorgan development. Development 125: 4645-4654.

ADOUTTE, A.B., G. LARTILLOT, N. DE ROSA, R. (1999). Animal evolution. The end of the intermediate taxa? Trends Genet 15: 104-108.

AGUINALDO, A.M.A., TURBEVILLE, J.M., LINFORD, L.S., RIVERA, M.C., GAREY J.R., RAFF, R.A. and LAKE, J.A. (1997). Evidence for a clade of nematodes, arthropods and other moulting animals. Nature 387: 489-493.

AKAM, M. (1987). The molecular basis for metameric pattern in the Drosophila 
embryo. Development 101: 1-22.

AKAM, M. (1995). Hox genes and the evolution of diverse body plans. Philos Trans $R$ Soc Lond B Biol Sci349: 313-319.

ARENDT, D. (2005). Genes and homology in nervous system evolution: Comparing gene functions, expression patterns, and cell type molecular fingerprints. Theory in Biosciences 124: 185-197.

BAGUÑA, J. and RIUTORT, M. (2004). The dawn of bilaterian animals: the case of acoelomorph flatworms. BioEssays 26: 1046-1057.

BAMBACH, R.K., BUSH, A.M. and ERWIN, D.H. (2007). Autecology and the filling of ecospace: Key metazoan radiations. Palaeontology 50: 1-22.

BERG, G. (1985). Annulonemertes gen. nov., a new segmented hoplonemertean. In The origins and relationships of lower invertebrates, (ed. CONWAY-MORRIS, S.GEORGE, J. D.GIBSON, R. and PLATT, H. M.). Clarendon Press, Oxford.

BISHOP, S.A., KLEIN, T., ARIAS, A.M. and COUSO, J.P. (1999). Composite signalling from Serrate and Delta establishes leg segments in Drosophila through Notch. Development 126: 2993-3003.

BORRADAILE, L.A., POTTS, F.A., EASTHAM, L.E.S. and SAUNDERS, J.T. (1963). The Invertebrata. Cambridge University Press, Cambridge.

BRAY, S.J. (2006). Notch signalling: a simple pathway becomes complex. Nat Rev Mol Cell Biol 7: 678-689.

BRIGGS, D.E.G., FORTEY, R.A. and WILLS, M.A. (1992). Morphological Disparity in the Cambrian. Science 256: 1670-1673.

BROMHAM L, P.D. (2003). The modern molecular clock. Nat Rev Genet. 4: 216224.

BRUSCA, R.C. and BRUSCA, G.J. (2003). Invertebrates. Sinauer Associates, Sunderland.

BUDD, G.E. (2001). Why are arthropods segmented? Evolution \& Development 3: 332-342.

BUTTERFIELD, N.J. (1994). Burgess shale-type fossils from a lower cambrian shallow-shelf sequence in northwestern Canada. Nature 369: 477-479.

BUTTERFIELD, N.J. (2007). Macroevolution and macroecology through deep time. Palaeontology 50: 41-55.

CAMPUZANO, S. and MODOLELL, J. (1992). Patterning of the Drosophila nervous system: the achaete-scute gene complex. Trends Genet 8: 202-208.

CARROLL, S.B. (1990). Zebra patterns in fly embryos: activation of stripes or repression of interstripes? Ce//60: 9-16.

CARROLL, S.B., GRENIER, J.K. and WHEATHERBEE, S.D. (2001). From DNA to diversity. Blackwell, Massachusetts.

CHIPMAN, A.D. and AKAM, M. (2008). The segmentation cascade in the centipede Strigamia maritima: Involvement of the Notch pathway and pair-rule gene homologues. Developmental Biology 319: 160-169.

CHITNIS, A., HENRIQUE, D., LEWIS, J., ISH-HOROWICZ, D. and KINTNER, C. (1995). Primary neurogenesis in Xenopus embryos regulated by a homologue of the Drosophila neurogenic gene Delta. Nature 375: 761-766.

CHOE, C.P., MILLER, S.C. and BROWN, S.J. (2006). A pair-rule gene circuit defines segments sequentially in the short-germ insect Tribolium castaneum. Proc. Natl. Acad. Sci. USA 103: 6560-6564.

ChOURROUT, D., DELSUC, F., ChOURROUT, P., EDVARDSEN, R.B., RENTZSCH, F., RENFER, E., JENSEN, M.F., ZHU, B., DE JONG, P., STEELE, R.E. et al. (2006). Minimal ProtoHox cluster inferred from bilaterian and cnidarian Hox complements. Nature 442: 684-687.

COHN, M.J. and TICKLE, C. (1996). Limbs: a model for pattern formation within the vertebrate body plan. Trends Genet 12: 253-257.

COHN, M.J. and TICKLE, C. (1999). Developmental basis of limblessness and axial patterning in snakes. Nature 399.

COLLINS, A.G. and VALENTINE, J.W. (2001). Defining phyla: evolutionary pathways to metazoan body plans. Evolution \& Development 3: 432-442.

CONWAY-MORRIS, S., GEORGE, J.D., GIBSON, R. and PLATT, H.M. (1985). The origins and relationships of lower invertebrates. Clarendon press, Oxford.

COOK, C.E., JIMENEZ, E., AKAM, M. and SALO, E. (2004). The Hox gene complement of acoel flatworms, a basal bilaterian clade. Evol Dev6: 154-163.

COUSO, J.P., BISHOP, S.A. and MARTINEZ ARIAS, A. (1994). The wingless signalling pathway and the patterning of the wing margin in Drosophila.
Development 120: 621-636.

COUSO, J.P., KNUST, E. and MARTINEZ ARIAS, A. (1995). Serrate and wingless cooperate to induce vestigial gene expression and wing formation in Drosophila. Curr Bio/5: 1437-1448.

CUBAS, P., DE CELIS, J.F., CAMPUZANO, S. and MODOLELL, J. (1991) Proneural clusters of achaete-scute expression and the generation of sensory organs in the Drosophila imaginal wing disc. Genes Dev 5: 996-1008.

DE CELIS, J.F., BRAY, S. and GARCIA-BELLIDO, A. (1997). Notch signalling regulates veinlet expression and establishes boundaries between veins and interveins in the Drosophila wing. Development 124: 1919-1928.

DE CELIS, J.F., TYLER, D.M., DE CELIS, J. and BRAY, S.J. (1998). Notch signalling mediates segmentation of the Drosophila leg. Development 125: 4617-4626.

DE ROBERTIS, E.M. (2008). Evo-Devo: Variations on Ancestral Themes. Ce//132: 185-195.

DE ROSA, R., GRENIER, J.K., ANDREEVA, T., COOK, C.E., ADOUTtE, A., AKAM, M., CARROLL, S.B. and BALAVOINE, G. (1999). Hox genes in brachiopods and priapulids and protostome evolution. Nature 399: 772-776.

DENES, A.S., JEKELY, G., STEINMETZ, P.R.H., RAIBLE, F., SNYMAN, H., PRUD'HOMME, B., FERRIER, D.E.K., BALAVOINE, G. and ARENDT, D. (2007). Molecular architecture of annelid nerve cord supports common origin of nervous system centralization in bilateria. Ce//129: 277-288.

DONG, X.-P., DONOGHUE, P.C.J., CHENG, H. and LIU, J.-B. (2004). Fossil embryos from the Middle and Late Cambrian period of Hunan, south China. Nature 427: 237-240.

DONOGHUE, P.C.J. and BENTON, M.J. (2007). Rocks and clocks: calibrating the Tree of Life using fossils and molecules. Trends in Ecology \& Evolution22: 424 431.

DROSER, M.L. and GEHLING, J.G. (2008). Synchronous aggregate growth in an abundant new Ediacaran tubular organism. Science 319: 1660-1662.

ERWIN, D.H. and DAVIDSON, E.H. (2002). The last common bilaterian ancestor Development 129: 3021-3032.

EYRE-WALKER, A. and KEIGHTLEY, P.D. (2007). The distribution of fitness effects of new mutations. Nature Reviews Genetics 8: 610-618.

FERRIER, D.E.K. and MINGUILLON, C. (2003). Evolution of the Hox/ParaHox gene clusters. Int. J. Dev. Biol. 47: 605-611.

FRENCH, V. (1983). Development and evolution of the insect segment. In Dev.and Evol. British Society for Developmental Biology Symposium, vol. 6 (ed. GOODWIN, B.), pp.161-193.

GARCIA-FERNANDEZ, J. (2005). Hox, ParaHox, ProtoHox: facts and guesses Heredity 94: 145-152.

GOULD, S.J. (1977). Ontogeny and Phylogeny. Harvard University Press, Massachusetts.

GOULD, S.J. (1989). Wonderful Life. Penguin Books, London.

HALANYCH, K.M. (2004). The new view of animal phylogeny. Annual Review of Ecology, Evolution, and Systematics 35: 229-256.

HAO, I., GREEN, R.B., DUNAEVSKY, O., LENGYEL, J.A. and RAUSKOLB, C. (2003). The odd-skipped family of zinc finger genes promotes Drosophila leg segmentation. Dev Bio/263: 282-95.

HARTENSTEIN, V. and POSAKONY, J.W. (1989). Development of adult sensilla on the wing and notum of Drosophila melanogaster. Development 107: 389 405.

HEITZLER, P. and SIMPSON, P. (1991). The choice of cell fate in the epidermis of Drosophila. Cel/64: 1083-1092.

HUGUES, N.C. (2003). Trilobite body patterning and the evolution of arthropod tagmosis. BioEssays 25: 386-395

INGHAM, P.W. (1988). The molecular genetics of embryonic pattern formation in Drosophila [published erratum appears in Nature 1988 Oct 20;335(6192):744] Nature 335: 25-34.

INGHAM, P.W. and FIETZ, M.J. (1995). Quantitative effects of hedgehog and decapentaplegic activity on the patterning of the Drosophila wing. Curr Bio/5: 432-440.

IRVINE, K.D. and WIESCHAUS, E. (1994). fringe, a Boundary-specific signaling molecule, mediates interactions between dorsal and ventral cells during Droso- 
phila wing development. Cel/79: 595-606.

JACOBS, D.K., HUGHES, N.C., FITZ-GIBBON, S.T. and WINCHELL, C.J. (2005). Terminal addition, the Cambrian radiation and the Phanerozoic evolution of bilaterian form. Evolution \& Development 7: 498-514.

JACOBS, D.K., WRAY, C.G., WEDEEN, C.J., KOSTRIKEN, R., DESALLE, R., STATON, J.L., GATES, R.D. and LINDBERG, D.R. (2000). Molluscan engrailed expression, serial organization, and shell evolution. Evolution \& Development 2: $340-347$

JEONG, S., REBEIZ, M., ANDOLFATTO, P., WERNER, T., TRUE, J. and CARROLL, S.B. (2008). The Evolution of Gene Regulation Underlies a Morphological Difference between Two Drosophila Sister Species. Cel/132: 783-793.

JEONG, S., ROKAS, A. and CARROLL, S.B. (2006). Regulation of Body Pigmentation by the Abdominal-B Hox Protein and Its Gain and Loss in Drosophila Evolution. Cel/125: 1387-1399.

JIANG, Y.J., AERNE, B.L., SMITHERS, L., HADDON, C., ISH-HOROWICZ, D. and LEWIS, J. (2000). Notch signalling and the synchronization of the somite segmentation clock. Nature 408: 475-479.

JIMENEZ-GURI, E., PHILIPPE, H., OKAMURA, B. and HOLLAND, P.W.H. (2007). Buddenbrockia is a Cnidarian worm. Science 317 : 116-118.

KÄSBAUER, T., TOWB, P., ALEXANDROVA, O., DAVID, C.N., DALL'ARMI, E., STAUDIGL, A., STIENING, B. and BÖTTGER, A. (2007). The Notch signaling pathway in the cnidarian Hydra. Developmental Biology 303: 376-390.

KIM, J., IRVINE, K.D. and CARROLL, S. (1995). Cell Interactions and Inductive Signals at the Dorsal/Ventral Boundary of the Developing Drosophila Wing. Ce// 82: 795-802.

KRAMATSCHEK, B. and CAMPOS-ORTEGA, J.A. (1994). Neuroectodermal transcription of the Drosophila neurogenic genes $\mathrm{E}(\mathrm{spl})$ and $\mathrm{HLH}-\mathrm{m} 5$ is regulated by proneural genes. Development 120: 815-826.

LAWRENCE, P.A. and JOHNSTON, P. (1989). Pattern formation in the Drosophila embryo: allocation of cells to parasegments by even-skipped and fushi tarazu. Development 105: 761-767.

LEE, P.N., PANG, K., MATUS, D.Q. and MARTINDALE, M.Q. (2006). A WNT of things to come: Evolution of Wnt signaling and polarity in cnidarians. Seminars in Cell \& Developmental Biology 17: 157-167.

LEMCHE, H. (1957). A New Living Deep-Sea Mollusc of the Cambro-Devonian Class Monoplacophora. Nature 179: 413-416.

LEWIS, J. (1998). Notch signalling and the control of cell fate choices in vertebrates. Seminars in Cell and Developmental Biology 9: 583-589.

LOWE, C.J., TERASAKI, M., WU, M., FREEMAN, R.M., RUNFT, L., KWAN, K., HAIGO, S., ARONOWICZ, J., LANDER, E., GRUBER, C. et al. (2006). Dorsoventral patterning in hemichordates: Insights into early chordate evolution. Plos Biology 4: 1603-1619.

LOWE, C.J., WU, M., SALIC, A., EVANS, L., LANDER, E., STANGE-THOMANN, N., GRUBER, C.E., GERHART, J. and KIRSCHNER, M. (2003). Anteroposterior Patterning in Hemichordates and the Origins of the Chordate Nervous System. Cel/113: 853-865

MARTINEZ-ARIAS, A. (1993). Development and patterning of the larval epidermis of Drosophila. In The development of Drosophila melanogaster, (ed. BATE, C. M. and MARTINEZ ARIAS, A.). Cold Spring Harbour Laboratory Press, pp.517608.

METZGER, R.J., KLEIN, O.D., MARTIN, G.R. and KRASNOW, M.A. (2008). The branching programme of mouse lung development. Nature 453: 745-750.

MITCHISON, G.J. (1980). A Model for Vein Formation in Higher Plants. Proceedings of the Royal Society of London. Series B, Biological Sciences (1934-1990) 207: 79-109.

PATEL, N.H., MARTINBLANCO, E., COLEMAN, K.G., POOLE, S.J., ELLIS, M.C. KORNBERG, T.B. and GOODMAN, C.S. (1989). Expression of Engrailed Proteins in Arthropods, Annelids, and Chordates. Ce//58: 955-968.

PETERSON, K.J. and BUTTERFIELD, N.J. (2005). Origin of the Eumetazoa: Testing ecological predictions of molecular clocks against the Proterozoic fossil record. Proc. Natl. Acad. Sci. USA 102: 9547-9552.

PETERSON, K.J., MCPEEK, M.A. and EVANS, D.A.D. (2005). Tempo and mode of early animal evolution: inferences from rocks, Hox, and molecular clocks. Paleobiology 31: 36-55.

PISTILLO, D., SKAER, N. and SIMPSON, P. (2002). Scute expression in Calliphora vicina reveals an ancestral pattern of longitudinal stripes on the thorax of higher Diptera. Development 129: 563-572.

POURQUIE, O. (2003). The segmentation clock: Converting embryonic time into spatial pattern. Science 301: 328-330.

PUEYO, I., LANFEAR, R. and COUSO, J.P. (2008). Ancestral Notch-mediated segmentation revealed in the cockroach Periplaneta americana. Proc. Nat/. Acad. Sci. USA 105: 16614-16619.

PUTNAM, N.H., SRIVASTAVA, M., HELLSTEN, U., DIRKS, B., CHAPMAN, J., SALAMOV, A., TERRY, A., SHAPIRO, H., LINDQUIST, E., KAPITONOV, V.V. et al. (2007). Sea anemone genome reveals ancestral eumetazoan gene repertoire and genomic organization. Science 317: 86-94.

RAUSKOLB, C. and IRVINE, K.D. (1999). Notch-mediated segmentation and growth control of the Drosophila leg. Developmental Biology 210: 339-350.

REICHERT, H. and SIMEONE, A. (2001). Developmental genetic evidence for a monophyletic origin of the bilaterian brain. Philosophical Transactions of the Royal Society B: Biological Sciences 356: 1533-1544.

RIDDLE, R.D., JOHNSON, R.L., LAUFER, E. and TABIN, C. (1993). Sonic hedgehog mediates the polarizing activity of the ZPA. Cel/75: 1401-1416.

RIVERA, A.S., GONSALVES, F.C., SONG, M.H., NORRIS, B.J. and WEISBLAT, D.A. (2005). Characterization of Notch-class gene expression in segmentation stem cells and segment founder cells in Helobdella robusta (Lophotrochozoa; Annelida; Clitellata; Hirudinida; Glossiphoniidae). Evolution \& Development 7 : 588-599.

RODRÍGUEZ-ESTEBAN, C., SCHWABE, J.W., DE LA PEÑA, J., FOYS, B., ESHELMAN, B. and BELMONTE, J.C. (1997). Radical fringe positions the apical ectodermal ridge at the dorsoventral boundary of the vertebrate limb. Nature 386: 360-366.

RUIZ-TRILLO, I., RIUTORT, M., LITTLEWOOD, D.T.J., HERNIOU, E.A. and BAGUÑA, J. (1999). Acoel flatworms: earliest extant Bilaterian Metazoans, not members of Platyhelminthes. Science 283: 1919-1923.

RUNNEGAR, B. and POJETA, J., JR. (1974). Molluscan Phylogeny: The Paleontological Viewpoint. Science 186: 311-317.

RYAN, J.F., MAZZA, M.E., PANG, K., MATUS, D.Q., BAXEVANIS, A.D., MARTINDALE, M.Q. and FINNERTY, J.R. (2007). Pre-bilaterian origins of the Hox cluster and the Hox code: evidence from the sea anemone, Nematostella vectensis. PLOS ONE2: e153.

SCHOPPMEIER, M. and DAMEN, W.G.M. (2005). Suppressor of Hairless and Presenilin phenotypes imply involvement of canonical Notch-signalling in segmentation of the spider Cupiennius salei. Developmental Biology280: 211-224.

SEILACHER, A., BUATOIS, L.A. and MANGANO, M.G. (2005). Trace fossils in the Ediacaran-Cambrian transition: Behavioral diversification, ecological turnover and environmental shift. Palaeogeography Palaeoclimatology Palaeoecology 227: 323-356

SIMON, M.A., BOWTELL, D.D.L., DODSON, G.S., LAVERTY, T.R. and RUBIN, G.M. (1991). Ras1 and a putative guanine nucleotide exchange factor perform crucial steps in signaling by the sevenless protein tyrosine kinase. Cel/67: 701716.

SKEATH, J.B. and CARROLL, S.B. (1991). Regulation of achaete-scute gene expression and sensory organ pattern formation in the Drosophila wing. Genes Dev 5: 984-995.

STOLLEWERK, A., SCHOPPMEIER, M. and DAMEN, W.G.M. (2003). Involvement of Notch and Delta genes in spider segmentation. Nature 423: 863-865.

TAUTZ, D. (2004). Segmentation. Developmental Cel/7: 301-312.

TECHNAU, U., RUDD, S., MAXWELL, P., GORDON, P.M.K., SAINA, M., GRASSO, L.C., HAYWARD, D.C., SENSEN, C.W., SAINT, R., HOLSTEIN, T.W. et al. (2005). Maintenance of ancestral complexity and non-metazoan genes in two basal cnidarians. Trends in Genetics 21: 633-639.

THAMM, K. and SEAVER, E.C. (2008). Notch signaling during larval and juvenile development in the polychaete annelid Capitella sp. I. Developmental Biology 320: 304-318

TOMLINSON, A. (1988). Cellular interactions in the developing Drosophila eye. Development 104: 183-193.

TRAINOR, P.A., ARIZA-MCNAUGHTON, L. and KRUMLAUF, R. (2002). Role of the Isthmus and FGFs in Resolving the Paradox of Neural Crest Plasticity and Prepatterning. Science 295: 1288-1291. 
VALENTINE, J.W. (1973). Coelomate Superphyla. Systematic Zoology22: 97-102.

VALENTINE, J.W. (2002). Prelude to the Cambrian explosion. Annual Review of Earth and Planetary Sciences 30: 285-306.

VALENTINE, J.W., JABLONSKI, D. and ERWIN, D.H. (1999). Fossils, molecules and embryos: new perspectives on the Cambrian explosion. Development 126 : 851-859.

WIGGLESWORTH, V.B. (1940). Local and General Factors in the Development of «Pattern» in Rhodnius Prolixus (Hemiptera). J Exp Bio/17: 180-201.

WILLMER, P. (1990). Invertebrate relationships. Cambridge University Press, Cambridge.
WOLPERT, L. (2002). Limb patterning: Reports of model's death exaggerated Current Biology 12: 628-630.

WULBECK, C. and SIMPSON, P. (2000). Expression of achaete-scute homologues in discrete proneural clusters on the developing notum of the medfly Ceratitis capitata, suggests a common origin for the stereotyped bristle patterns of higher Diptera. Development 127: 1411-1420.

ZAKANY, J., KMITA, M., ALARCON, P., J.L., D.L.P. and DUBOULE, D. (2001). Localized and transient transcription of Hox genes suggests a link between patterning and the segmentation clock. Cel/106: 207-217.

\section{Further Related Reading, published previously in the Int. J. Dev. Biol.}

See our recent Special Issue Fertilization, in honor of David L. Garbers and edited by Paul M. Wassarman and Victor D. Vacquier at: http://www.ijdb.ehu.es/web/contents.php?vol=52\&issue =5-6

See our recent Special Issue Evolution \& Development, edited by Jaume Baguña and Jordi García-Fernández at: http://www.ijdb.ehu.es/web/contents.php?vol=47\&issue $=7-8$

On the origin of pattern and form in early Metazoans

Frederick W. Cummings

Int. J. Dev. Biol. (2006) 50: 193-208

Adaptive walks in a gene network model of morphogenesis: insights into the Cambrian explosion.

Ricard V Solé, Pau Fernández and Stuart A Kauffman

Int. J. Dev. Biol. (2003) 47: 685-693

Morphological and developmental macroevolution: a paleontological perspective.

James W Valentine and David Jablonski

Int. J. Dev. Biol. (2003) 47: 517-522

The Cambrian «explosion» of metazoans and molecular biology: would Darwin be satisfied?

Simon Conway-Morris

Int. J. Dev. Biol. (2003) 47: 505-515

Vertebrate somitogenesis: a novel paradigm for animal segmentation?

Olivier Pourquié

Int. J. Dev. Biol. (2003) 47: 597-603

\section{Segmentation: mono- or polyphyletic?}

Elaine $C$ Seaver

Int. J. Dev. Biol. (2003) 47: 583-595

The first bilaterian organisms: simple or complex? New molecular evidence J Baguna, I Ruiz-Trillo, J Paps, M Loukota, C Ribera, U Jondelius, M Riutort Int. J. Dev. Biol. (2001) 45: S133-S134

Cyclic transcription of Hox genes suggests a link between patterning and the segmentation clock

József Zákány, Marie Kmita, José-Luis de la Pompa and Denis Duboule Int. J. Dev. Biol. (2001) 45: S23-S23

Cell lineage analysis of pattern formation in the Tubifex embryo. II. Segmentation in the ectoderm.

A Nakamoto, A Arai and T Shimizu

Int. J. Dev. Biol. (2000) 44: 797-805

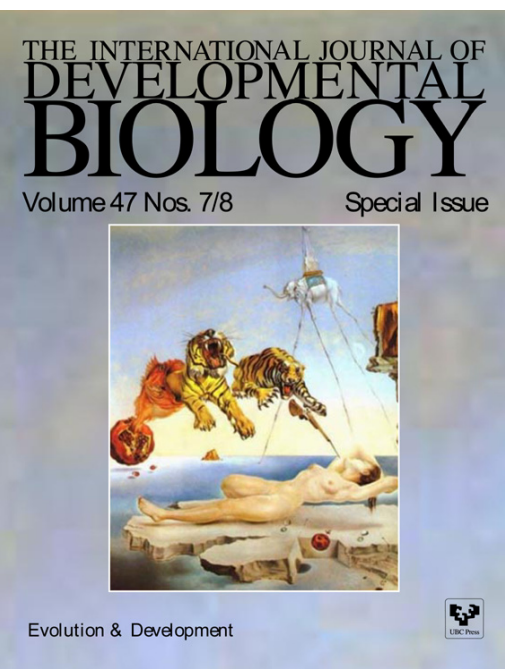

5 yr ISI Impact Factor $(2008)=3.271$

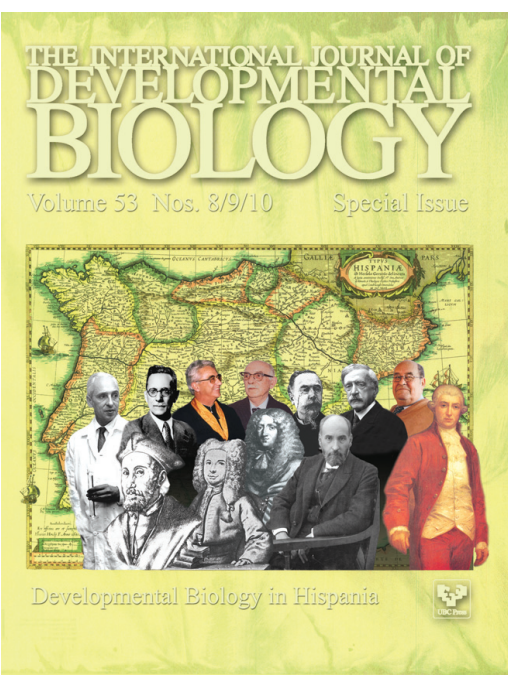

